\title{
Spectrum of central nervous system infections in a tertiary health care centre in Cameroon
}

\author{
Daniel Gams Massi ${ }^{1,2^{*}}$ (D) Marcel Roger Rodrigue Mintyene Mintyene ${ }^{3}$, Annick Mélanie Magnerou ${ }^{3,4}$, \\ Seraphine Mojoko Eko ${ }^{1}$, Caroline Kenmegne ${ }^{2}$, Salomon Mbahe ${ }^{2}$, Prince Eliot Sounga Bandzouzi ${ }^{5}$, \\ Hugo Bertrand Mbatchou Ngahane $e^{2,3}$ and Njankouo Yacouba Mapoure 2,3
}

\begin{abstract}
Background: Central nervous system (CNS) infections are serious and debilitating diseases with significant mortality, and high prevalence in the context of human immunodeficiency virus (HIV) pandemic in Africa. However, their diagnosis remains challenging due to outdated technical platform. We aimed to determine the frequency of CNS infection and to describe the epidemiological, clinical and outcome of this at the Douala General Hospital (DGH), Cameroon. To carry out this study, we collected the medical records of patients hospitalized for CNS infections in the internal medicine department of DGH from January 2015 to December 2019.

Results: Among 8430 files reviewed, 336 cases of CNS infection were identified giving a frequency of CNS infection of 3.99\% among which 204 files were included in the study (54.4\% were male). HIV infection was found in 147 patients $(72.1 \%)$ with $38.1 \%(n=56)$ of them on regular follow-up. The most common clinical signs were fever $(84.8 \%)$, headache (68.6\%), meningeal syndrome (38.7\%), and seizures (36.3\%). Cerebral toxoplasmosis (24.5\%), cryptococcal meningitis (21.1\%), and acute bacterial meningitis (8.3\%) were leading aetiologies. Of the 143 CSF samples, $70.6 \%$ $(n=101)$ were sterile. The in-hospital mortality rate was $23.5 \%$ with CNS infection of unknown cause $(22.1 \%)$ be independently associated to this $[\mathrm{OR}=2.24 ; 95 \% \mathrm{Cl} 1.04-4.80, p=0.039]$.

Conclusion: Clinical presentations of CNS infections are same with classical data. HIV-related opportunistic infections are the main aetiologies. About one over four patients with CNS died. Two thirds of CSF are sterile using basic laboratory assessment giving a need to identify simple tests to increase sensibility and specificity of diagnostic tools in our setting.
\end{abstract}

Keywords: CNS infection, HIV, Cerebral toxoplasmosis, Douala, Cameroon

\section{Background}

Central nervous system (CNS) infections are potentially life-threatening conditions that constitute a diagnostic and therapeutic emergency [1-5]. It is a group of neurological conditions with varying symptoms depending on the type of infection, the pathogen involved and the site

\footnotetext{
*Correspondence: danny.gamsmassi@gmail.com

${ }^{2}$ Internal Medicine Department, Douala General Hospital, PO Box: 4856, Douala, Cameroon

Full list of author information is available at the end of the article
}

in which they occur $[4,6]$. These infections are caused by microorganisms (viruses, bacteria, fungi, protozoa); macro-organisms and microparticles (prions) [3, 6-8]. The causative organisms vary depending on their location in the CNS, geographic exposure, vaccination status, age, surgical procedures and immune status [2, 8]. Knowledge of the most common aetiologies is important for the appropriate choice of antimicrobial therapy, which must be instituted promptly to reduce morbidity and mortality and prevent long-term neurological sequelae [2, 3]. CNS 
infections are relatively rare in developed countries but remain a public health problem in developing countries $[1,9,10]$.

The global incidence of CNS infections between 1990 and 2016 is estimated at 389/100,000 [12]. In Africa, pooled data on CNS infections are scarce. Meningitis epidemics have, however, been declared in the countries of the Sub-Saharan meningitis belt [13-16]. In Nigeria, 393,614 cases of meningitis were reported between 1991 and 2011 by the World Health Organization (WHO) [17]. Immunosuppression is frequently associated to CNS infections. Thus, patients infected with the Human Immunodeficiency Virus (HIV) will be more exposed to these infections [18-20]. Between 2006 and 2016, 102 cases of cryptococcal meningitis were reported in Togo [20]. In Cameroon, between 2004 and 2009, cerebral toxoplasmosis (32\%) and cryptococcal meningitis (25\%) were reported as commonest CNS infections in HIV immunocompromised patients [19]. However, Streptococcus pneumonia (46\%) and Neisseria meningitis (30\%) were the main aetiologies among 135 cases of meningitis reported in Cameroon [21].

Morbidity and mortality associated with CNS infections is higher compared to infections of other systems [5]. Despite remarkable progress in their prevention and management, $\mathrm{CNS}$ infections remain a major cause of death, particularly in developing countries and in immunocompromised patients [7]. Without treatment, the mortality from bacterial meningitis is close to $100 \%$, while with adequate treatment the mortality is reduced to $4.2 \%$ [22]. The overall mortality from viral encephalitis is estimated between $3.8 \%$ and $7.4 \%$ with an incidence of 2.2/100,000 in adults and 6.3/100,000 at any age [23]. This study aims to provide data in a resource limited area for decision-making and improvement of the management of this public health concern.

\section{Methods}

A retrospective cohort study was conducted in the internal medicine department of the Douala General Hospital (DGH). Medical files were reviewed for patients aged 16 years and above, hospitalized between January 1, 2015 and December 31, 2019 for CNS infection diagnosed via neuroimaging (brain CT scan and MRI) with and without cerebrospinal fluid (CSF) analysis. All patients performed at least brain CT scan/MRI and/or CSF analysis. Each file stored in the archives was recorded in a register, as well as in a computer which contained the hospital reports of each patient. Incomplete files, especially without neuroimaging and/or CSF analysis results were excluded. Ethical approval was obtained from institutional ethics committee of the University of Douala (No. 2162CEI-UDo/01/2020/T).
The following data were collected from selected medical files: (1) sociodemographic data: age, gender, profession, marital status; (2) comorbidities: HIV, diabetes, hypertension, chronic kidney disease (CKD); (3) clinical data: neurological and extra-neurological signs; (4) paraclinical workups: neuroimaging (brain CT scan or MRI), CSF analysis when done, and other biological testing, such as CBC, CRP, blood culture; and (5) outcome: mean length of hospitalization and mortality.

The CSF analysis carried out by the laboratory of the DGH are classically: biochemistry (protein and glucose level), cell count (leucocytes and red blood cells), direct detection (Gram stain, India ink, and Ziehl-Neelsen stain), culture on blood or chocolate agar (bacteria), Lowenstein-Jensen medium (Mycobacterium tuberculosis), Sabouraud dextrose agar (fungi), soluble bacterial antigens, cryptococcal antigens, and Veneral disease research laboratory (VDRL)/Treponemal Pallidum Hemagglutination assay (TPHA). When requested, a real-time polymerase chain reaction (PCR) for Mycobacterium tuberculosis also called Xpert MTB/RIF Molecular Beacon Assay was performed at the laboratory of the Regional Delegation of Public Health of the Littoral. Hypoglycorachia was defined as a CSF glucose level less than half of the glycaemia; hyperproteinorachia was defined as a CSF protein level in the CSF greater than $0.45 \mathrm{~g} / \mathrm{L}$; and pleocytosis was considered as a white cell count $>5$ cells $/ \mathrm{mm}^{3}$.

\section{Statistical analysis}

The data collected was recorded in our database and was analysed using SPSS software version 23.0. Categorical variables were expressed as frequencies with percentages. Continuous variables were presented as mean \pm standard deviation (SD). $X^{2}$ and Student tests were used to compare categorical and continuous variables, respectively. Multivariate analysis using logistic regression was performed to determine factors associated to death. Results were considered significant for a $p$-value $<0.05$.

\section{Results}

Out of the 8430 files reviewed, 336 cases of CNS infection were identified, of which 204 met the inclusion criteria. From 2015 to 2019, the hospital-based frequency of CNS infections ranged from $2.2 \%$ to $2.6 \%$ (Fig. 1).

The mean age of the patients was $42.6 \pm 13.79$ years (16-84 years). The most common age groups were $30-40$ years $(29.9 \%)$ and $40-50$ years $(28.4 \%)$. Male patients accounted for $54.4 \%$ of cases. HIV infection was found in 147 cases $(72.1 \%)$ with $61.9 \%$ of them not on regular follow-up with highly active antiretroviral therapy (HAART) (Table 1). 


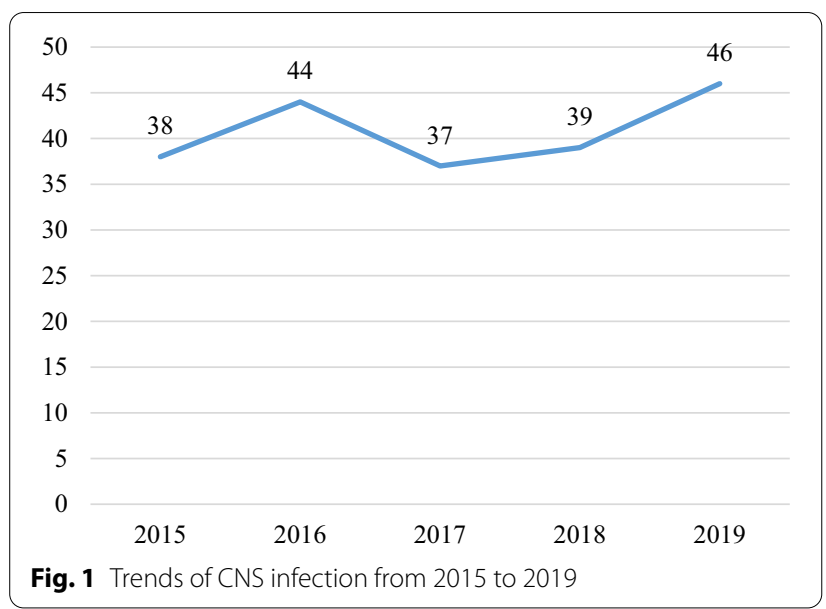

Table 1 Risk factors and comorbidities

\begin{tabular}{llll}
\hline Variables & Followed-up & Not followed-up & Total (\%) \\
\hline HIV & 91 & 56 & 72.1 \\
Alcohol & 58 & - & 28.4 \\
Other surgery & 15 & - & 7.4 \\
Smoking & 12 & - & 5.9 \\
Hypertension & 9 & 21 & 14.7 \\
Diabetes & 6 & 4 & 4.9 \\
CKD & 3 & 8 & 5.4 \\
Brain surgery & 1 & - & 0.5 \\
\hline
\end{tabular}

CKD chronic kidney disease, HIV human immunodeficiency virus

The most common neurological signs were headache (68.6\%), impaired consciousness (44.1\%), signs of meningeal irritation (38.7\%), and epileptic seizures (36.3\%), while altered general state (93.1\%), fever (84.8\%) and vomiting $(35.8 \%)$ were main extra-neurological signs (Table 2).

Neuroimaging was performed in 177 patients (brain CT scan =131; brain MRI=46). Results were abnormal in 117 cases with brain mass representing the commonest lesion reported. These abnormalities were found in $65.6 \%$ and $67.4 \%$ of brain CT scan and brain MRI, respectively. Lumbar puncture with CSF analysis was performed in 143 patients. Results showed hypoglycorachia $(n=67$; $46.6 \%)$, hyperproteinorachia $(n=103 ; 77.4 \%)$, and pleiocytosis $(n=42 ; 29.4 \%)$. CSF microbiological analysis was positive for Cryptococcus neoformans $(n=38)$, Neisseria meningitidis $(n=1)$, Streptococcus pneumoniae $(n=1)$ and Pseudomonas aeruginosa $(n=1)$. No acidfast bacilli were detected through the Ziehl-Neelsen stain. PCR was positive for Mycobacterium tuberculosis in three cases. Among the patients with HIV, the mean CD4 count (in 94 patients) was less than 350 cells $/ \mathrm{mm}^{3}$ in $92.3 \%$ of cases. The most frequent aetiologies were
Table 2 Clinical manifestations in patients with CNS infections

\begin{tabular}{lrr}
\hline Clinical signs & $\boldsymbol{n}$ & $\%$ \\
\hline Neurological signs & 140 & \\
Headaches & 90 & 68.6 \\
Impaired consciousness & 79 & 44.1 \\
Meningeal signs & 74 & 38.7 \\
Seizures & 59 & 36.3 \\
Focal neurological deficits & & 28.9 \\
Extra-neurological signs & 190 & \\
Altered general state & 173 & 93.1 \\
Fever & 73 & 84.8 \\
Vomiting & 52 & 35.8 \\
Respiratory distress & 42 & 25.5 \\
Gastro-intestinal tract signs & 28 & 20.6 \\
Dehydration & 17 & 13.7 \\
Clinical anaemia & 7 & 8.3 \\
Skin rash & & 3.4 \\
\hline
\end{tabular}

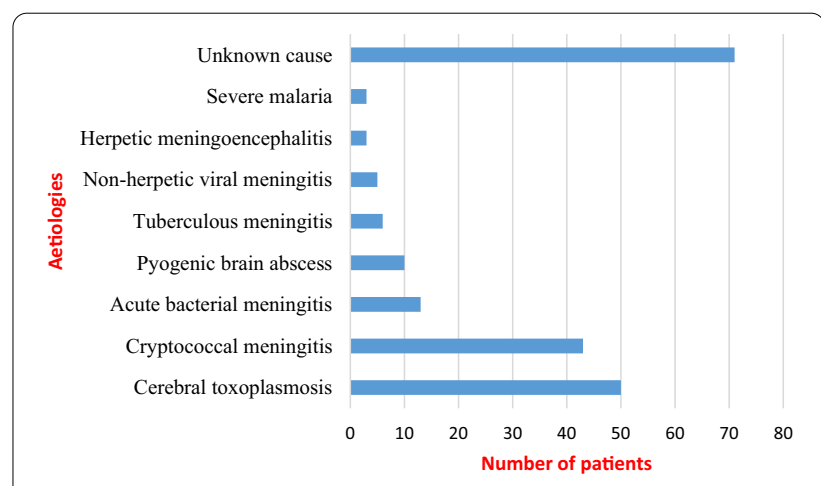

Fig. 2 Aetiologies of CNS infections

cerebral toxoplasmosis (24.5\%) and cryptococcal meningitis (21.1\%), while unknown aetiology was founded in $34.8 \%$ of cases (Fig. 2).

The mean length of hospitalization was $9.5 \pm 7.1$ days with an in-hospital mortality was $23.5 \%$. In the univariate analysis, factors associated with in-hospital mortality were: age groups of 30-40 ( $p=0.012), 40-50(p=0.011)$ and CNS of unknown aetiology $(p=0.006)$. After multivariate analysis, only CNS infection of unknown aetiology was independently associated to the in-hospital mortality (OR $=2.24,95 \%$ CI $1.04-4.8), p=0.039)$ (Table 3).

\section{Discussion}

This study reviewed cases of CNS infections in a referral hospital in Cameroon and aimed to determine his frequency and to describe their characteristics. There was a slight increase in the number of cases reported from 
Table 3 Predictive factors of mortality

\begin{tabular}{|c|c|c|c|c|}
\hline Variables & Crude OR $(95 \% \mathrm{Cl})$ & $p$ value & Adjusted OR (95\% Cl) & $p$ value \\
\hline Age [20-30] & Ref. & - & - & - \\
\hline Age [30-40] & $0.16(0.04-0.64)$ & 0.012 & $0.75(0.24-2.52)$ & 0.632 \\
\hline Age [40-50] & $0.15(0.03-0.64)$ & 0.011 & $0.69(0.22-2.33)$ & 0.535 \\
\hline Age [50-60] & $0.31(0.06-1.14)$ & 0.135 & $1.30(0.36-4.89)$ & 0.686 \\
\hline Age [60-70] & $0.25(0.05-1.31)$ & 0.102 & $0.80(0.18-3.40)$ & 0.759 \\
\hline Age $\geq 70$ & - & - & $3.38(0.63-20.33)$ & 0.164 \\
\hline Female & Ref. & - & - & - \\
\hline Male & $1.10(0.57-2.11)$ & 0.770 & - & - \\
\hline HIV & $0.55(0.27-1.10)$ & 0.094 & $1.04(0.42-2.71)$ & 0.927 \\
\hline Diabetes & $0.80(0.16-3.92)$ & 0.788 & - & - \\
\hline Hypertension & $1.48(0.62-3.5)$ & 0.368 & - & - \\
\hline CKD & $2.90(0.84-9.98)$ & 0.090 & $2.05(0.50-7.98)$ & 0.300 \\
\hline CD4 count $\leq 200 / \mathrm{mm}^{3}$ & $1.6(0.33-7.56)$ & 0.553 & - & - \\
\hline Cerebral toxoplasmosis & $0.21(0.07-0.64)$ & 0.006 & - & - \\
\hline Cryptococcal meningitis & $1.56(0.73-3.30)$ & 0.246 & - & - \\
\hline Bacterial meningitis & $1.23(0.31-4.84)$ & 0.764 & - & - \\
\hline Unknown aetiology & $2.52(1.30-4.88)$ & 0.006 & $2.24(1.04-4.80)$ & 0.039 \\
\hline
\end{tabular}

CKD chronic kidney disease, HIV human immunodeficiency virus

2015 to 2019 . HIV was the main comorbidity associated to CNS infections. The main aetiologies were HIV related opportunistic CNS infections. The in-hospital mortality was significant.

In Sub-Saharan Africa (SSA), CNS infections are frequent causes of admission in neurology [24]. The overall intra-hospital prevalence of CNS infections in this study was underestimated. A recent study done in Cameroon including patients from outpatient department and hospitalization in two referral hospitals reported a prevalence of $11.3 \%$ in 2018 in Cameroon [11]. The flow of patients hospitalized for CNS infection does not reflect the reality.

Young adults represented the main age group. Several studies in Africa reported similar data [19, 25-27]. In Europe, Erdem et al. found a mean higher than our findings [28]. This gap could be explained by the difference in demographical characteristics of African and European populations. In addition, the most frequent age groups in this study are similar to the HIV most affected age groups in the Cameroonian population (Cameroon populationbased HIV impact assessment, 2017). The male predominance found in this study was consistent with other studies [26, 29-31]. Genetic and hormonal difference may contribute to this gender difference. Oestrogens was described to play a protective role against infections by reducing the inflammatory response [32]. Close to three quarters of patients were PLWH. Similar results were reported in Ivory Coast and Mali [27, 33].
Clinical manifestations are often similar to those of classical data [4]. In this study, the neurological signs were mainly: headache, impaired consciousness, meningeal syndrome, and seizures. Diarra et al. found meningeal syndrome in $34.5 \%$ of cases [27]. Meningeal syndrome is a clinical expression of the inflammatory reaction produced when the meninges are invaded by a pathogen. Thus, a frank meningeal syndrome would reflect a significant inflammatory response of the CNS. The population in this study is characterized by a high frequency of HIV infection low immunity (CD4 cells less than $350 / \mathrm{mm}^{3}$ ). This could explain the lower inflammatory response, hence the low frequency of patients with meningeal syndrome [34].

The leading aetiologies were cerebral toxoplasmosis (24.5\%), cryptococcal meningitis (21.1\%), and acute bacterial meningitis (5.9\%). These findings are consistent with a study done by Luma et al. in 2013, which found cerebral toxoplasmosis (32.3\%) and cryptococcal meningitis $(25 \%)$ as the commonest aetiologies [19]. Given the endemic context of HIV and the high frequency of people living with HIV (PLWH) in our context, opportunistic infections such as cerebral toxoplasmosis and cryptococcal meningitis remain very frequent [35]. The occurrence of opportunistic infections is favoured by the low rate of patients with HIV under regular HAART in this population. In more than one-third of cases, the aetiology remains undetermined compared to $8.8 \%$ of cases reported in Europe [28]. This diagnostic gap reflects the difficulty encountered in resource-limited settings [3]. 
These difficulties are accentuated by the fact that more than a quarter of these patients are referred from primary health centres, where patients receive empirical antibiotics without any microbiological evidence. More efficient diagnostic tools may contribute to improve the identification of pathogens.

In 2013, Luma et al. reported a mortality of $49 \%$ in PLWH which is more than two time higher than our finding [19]. Several studies have reported mortality rates greater than $10 \%[21,26,27,36]$. Cerebral toxoplasmosis represented the lowest case fatality rate in this series. In multivariate analysis, there was a statistically significant association between the occurrence of death and the undetermined aetiologies (adjusted $\mathrm{OR}=2.24 ; p=0.039$ ). This could be explained by the fact that without knowing of the causes, specific treatment cannot be instituted, thereby increasing the risk of death [1].

This study places the foundations for epidemiological data on CNS infections in Cameroon. However, the retrospective design of this study leads to data collection challenges with up to 132 incomplete medical files excluded. This could have impacted the reliability of results. In addition, this study was conducted in one hospital, and therefore, data cannot be generalized in the entire community.

\section{Conclusions}

Clinical presentations of CNS infections are same with classical data. HIV-related opportunistic infections are the main aetiologies. Mortality remains high in our context. Two over third CSF are sterile using basic laboratory assessment giving a need to implement simple tests to increase sensibility and specificity of diagnostic tools in our setting.

\begin{abstract}
Abbreviations
CNS: Central nervous system; HIV: Human immune-deficiency virus; DGH: Douala general hospital; CSF: Cerebrospinal fluid; WHO: World Health Organization; CT: Computed tomography; MRI: Magnetic resonance imaging; CKD: Chronic kidney disease; CBC: Complete blood count; CRP: C-reactive protein; VDRL: Veneral disease research laboratory; TPHA: Treponemal Pallidum Hemagglutination assay; PCR: Polymerase chain reaction; MTB/RIF: Mycobacterium tuberculosis DNA and resistance to rifampicin; SD: Standard deviation; HAART: Highly active antiretroviral therapy; PLWH: People living with human immune-deficiency virus.
\end{abstract}

\section{Acknowledgements}

We are grateful to Ruth Ebongue, in charge of the medical records of the Internal Medicine department of the Douala General Hospital, for her complete collaboration.

\section{Authors' contributions}

Research project: conceptualization, DGM, MRRMM and NYM; methodology, DGM, MRRMM and NYM; software, DGM, MRRMM; validation, HBMN and NYM; investigation, DGM, MRRMM; resources, KC and MS; data curation, DGM and AMM; writing — original draft preparation, DGM and MRRMM; writing - review and editing, DGM, AMM, ESM, PESB; supervision, NYM; project administration,
DGM, HBMN and NYM. All authors have read and agreed to the published version of the manuscript.

Funding

Not applicable.

Availability of data and materials

Data can be made available upon reasonable request.

\section{Declarations}

\section{Ethics approval and consent to participate}

Ethical approval was obtained from institutional ethics committee of the University of Douala (No. 2162CEI-UDo/01/2020/T) of the 29th January, 2020. In this study, we reviewed the anonymized medical records of patients.

\section{Consent for publication}

Not applicable.

\section{Competing interests \\ Not applicable.}

\section{Author details}

${ }^{1}$ Faculty of Health Sciences, University of Buea, Buea, Cameroon. ${ }^{2}$ Internal Medicine Department, Douala General Hospital, PO Box: 4856, Douala, Cameroon. ${ }^{3}$ Faculty of Medicine and Pharmaceutical Sciences, University of Douala, Douala, Cameroon. ${ }^{4}$ Internal Medicine Department, Douala Gyneco-Obstetric and Paediatric Hospital, Douala, Cameroon. ${ }^{5}$ Department of Neurology, Marien Ngouabi University, Brazzaville, Republic of Congo.

Received: 26 September 2021 Accepted: 16 January 2022

Published online: 05 February 2022

\section{References}

1. Sarrazin J, Bonneville F, Martin-blondel G. Infections cérébrales. J Radiol Diagnostique Interv. 2019;93(6):503-20. https://doi.org/10.1016/j.jradio. 2012.03.003.

2. Riddell J, Shuman EK. Epidemiology of central nervous system infection. Neuroimaging Clin N Am. 2012;22(4):543-56.

3. Giovane RA. Central nervous system infections. Prim Care Clin Off Pract. 2018. https://doi.org/10.1016/j.pop.2018.05.007.

4. Ahmed MM. Clinical presentation and outcome of bacterial Meningitis in University Hospital. Adv Infect Dis. 2014;4:124-31.

5. Parikh V, Tucci V, Galwankar S. Infections of the nervous system. Int J Crit IIIn Inj Sci. 2012;2(2):82.

6. John CC, Carabin H, Montano SM, Bangirana P, Zunt JR, Peterson PK. Global research priorities for infections that affect the nervous system. Nature. 2015;527(7578):S178-86. https://doi.org/10.1038/nature16033.

7. Shih RY, Koeller KK. Bacterial, fungal, and parasitic infections of the central nervous system: radiologic-pathologic correlation and historical perspectives. Radiographics. 2015;35(4):1141-69. https://doi.org/10.1148/rg. 2015140317.

8. Giri A, Arjyal A, Koirala S, Karkey A, Dongol S, Thapa SD, Shilpakar O, Shrestha R, van Tan L, Thi Thuy Chinh BN, Krishna KCR, Pathak KR, Shakya M, Farrar J, Van Doorn HR, Basnyat B. Aetiologies of central nervous system infections in adults in Kathmandu, Nepal: a prospective hospitalbased study. Sci Rep. 2013;3:2382. https://doi.org/10.1038/srep02382.

9. Asiedu-bekoe F, Acheampong GK. Epidemiological dynamics of a bacterial meningitis outbreak in two districts in Northern Ghana. Open Access Libr J. 2016:3:1-12. https://doi.org/10.4236/oalib.1102993.

10. Zhao S, Lin Q, He D, Stone L. Meningitis epidemics shift in sub-Saharan belt. Int J Infect Dis. 2018;68:79-82. https://doi.org/10.1016/j.ijid.2018.01. 020

11. Mapoure NY, Doumbe J, Gams Massi D, Nyinyikua ST, Kuate TC, Luma $\mathrm{NH}$. Epidémiologie clinique des affections neurologiques dans la ville de Douala. Rev Méd Pharm. 2018:8:738-50.

12. Robertson FC, Lepard JR, Mekary RA, Davis MC, Yunusa I, Gormley WB, Baticulon RE, Mahmud MR, Misra BK, Rattani A, Dewan MC, Park KB. 
Epidemiology of central nervous system infectious diseases: a metaanalysis and systematic review with implications for neurosurgeons worldwide. J Neurosurg. 2018;1:1-20. https://doi.org/10.3171/2017.10. JNS17359.

13. Davis LE. Acute bacterial meningitis. Continuum (Minneapolis, Minn). 2018;24(5):1264-83. https://doi.org/10.1212/con.00000000000000660.

14. Hulten KG. Viral meningitis in the UK: time to speed up Risk factors in septic revisions following total hip arthroplasty. Lancet Infect Dis. 2018;18(9):930-1. https://doi.org/10.1016/S1473-3099(18)30287-1.

15. Paradowska-Stankiewicz I, Piotrowska A, Polsce WW. Epidemiological chronicle / kronika epidemiologiczna meningitis and encephalitis in Poland In 2015 Zapalenia Opon Mózgowo-Rdzeniowych I Zapalenia Mózgu. Przegl Epidemiol. 2017;71(4):493-500.

16. Chong H, Tan C. Epidemiology of central nervous system infections in Asia, recent trends. Neurol Asia. 2005;10:7-11.

17. Abdussalam AF, Qaffas Y. Spatiotemporal patterns and social risk factors of meningitis in Nigeria. Open Access Libr J. 2016;3:1-14.

18. Luma HN, Tchaleu BCN, Mapoure YN, Temfack E, Doualla MS, Halle MP, Joko HA, Koulla-Shiro S. Toxoplasma encephalitis in HIV/AIDS patients admitted to the Douala general hospital between 2004 and 2009: a cross sectional study. BMC Res Notes. 2013;6:146. https://doi.org/10.1186/ 1756-0500-6-146.

19. Luma HN, Tchaleu BC, Temfack E, Doualla MS, Ndenga DP, Mapoure YN, Njamnshi AK, Djientcheu VD. HIV-associated central nervous system disease in patients admitted at the Douala general hospital between 2004 and 2009: a retrospective study. AIDS Res Treat. 2013;2013: 709810. https://doi.org/10.1155/2013/709810.

20. Wateba IM, Balaka A, Bawe AL, Kotosso A. Cryptococcal meningitis of the HIV-infected Person in Lomé: about 102 cases over 10 years. World J AIDS. 2017;7:217-22.

21. Mapoure YN, Luma HN, Gnonlonfoun D, Ossou-quiet PM, Biloa X, Doumbe JN, Mbatchou HBN, Tchaleu BCN, Fonsah JY, Mouelle AS, Njamnshi AK. Spectrum of meningitis in adult at the Douala general hospital. World J Neurosci. 2014;4:144-51.

22. Li C, Feng W, Lin A, Zheng G, Wang Y, Han Y, Zhong J, Bi J, Luo Q, Zhao F. Clinical characteristics and etiology of bacterial meningitis in Chinese children $>28$ days of age, January 2014-December 2016: a multicenter retrospective study. Int J Infect Dis. 2018;74:47-53. https://doi.org/10. 1016/j.ijid.2018.06.023.

23. Ben F, Abukhattab M, Ghazouani H, Khalil O, Gohar A, Al H, et al. International Journal of Infectious Diseases Epidemiology and clinical outcomes of viral central nervous system infections. Int J Infect Dis. 2018;73:85-90. https://doi.org/10.1016/j.jijid.2018.06.008.

24. Andriantseheno LM, Andrianasy TF. Hospital based study on neurological disorders in Madagascar. Data from the northwestern part of the island. AJNS, 1997;16(2).

25. Rachid MG. Infections du système nerveux au service de neurologie du centre hospitalier universitaire Mohammed VI de Marrakech [Thèse de médecine]. Marrakech: Université CADDI AYYAD; No. 74: 2014, p. 140.

26. Ouattara B, Eholie SP, Adoubryn KD, Kra O, Tia H, Kouadio-Yapo C, Edo $\checkmark$, Ouhon J. Étude retrospective des méningites bactériennes et à cryptocoques chez des sujets adultes infectés par le VIH à Abidjan (Côte d'Ivoire). J Mycol Med. 2007;17:82-6. https://doi.org/10.1016/j.mycmed. 2007.02.003.

27. Diarra B. Atteintes cérébroméningées dans le service des Maladies Infectieuses et Tropicales du CHU du Point G [Thèse de médecine]. Point G: Université de Bamako; 2012;1-60.

28. Erdem H, Inan A, Guven E, Hargreaves S, Larsen L, Shehata G, et al. The burden and epidemiology of community-acquired central nervous system infections: a multinational study. Eur J Clin Microbiol Infect Dis. 2017;10:36.

29. Akhvlediani T, Bautista CT, Shakarishvili R, Tsertsvadze T, Imnadze P, Tatishvili N, et al. Etiologic agents of central nervous system infections among febrile hospitalized patients in the Country of Georgia. PLOS ONE. 2014;9(11):5-11.

30. Ho Dang Trung N, Le Thi Phuong T, Wolbers M, et al. Aetiologies of central nervous system infection in Viet Nam: a prospective provincial hospitalbased descriptive surveillance study. PLoS ONE. 2012;7(5):e37825. https:// doi.org/10.1371/journal.pone.0037825.
31. Godjedo TP, Paraiso MN, Agbankpe AJ, Dougnon TV, Degbey C, Ahoyo $A$, et al. Case-by-case surveillance for bacterial meningitis in benin: data analysis 2016 to 2018. Open J Epidemiol. 2020;1-14.

32. Schurz H, Salie M, Tromp G, Hoal EG, Kinnear CJ, Möller M. The X chromosome and sex-specific effects in infectious disease susceptibility. Hum Genomics. 2019;13:1-12.

33. Sarrazin JL, Bonneville F, Martin-Blondel G. Brain infections. Diagn Interv Imaging. 2012;93(6):473-90. https://doi.org/10.1016/j.diii.2012.04.020.

34. Forrester JV, Mcmenamin PG, Dando SJ. CNS infection and immune privilege. Nat Rev Neurosci. 2018;19:655-71. https://doi.org/10.1038/ S41583-018-0070-8.

35. Bowen LN, Smith B, Reich D, Quezado M, Nath A. HIV-associated opportunistic CNS infections: pathophysiology, diagnosis and treatment. Nat Rev Neurol. 2016;12(11):662-74. https://doi.org/10.1038/nrneurol.2016. 149.

36. Essayagh T, Essayagh M, Essayagh S. Vital prognostic factors of bacterial meningitis in Morocco: a 12-year study. J Clin Exp Pathol. 2017;7(4):318. https://doi.org/10.4172/2332-0877.1000318.

\section{Publisher's Note}

Springer Nature remains neutral with regard to jurisdictional claims in published maps and institutional affiliations.

\section{Submit your manuscript to a SpringerOpen ${ }^{\circ}$ journal and benefit from:}

- Convenient online submission

- Rigorous peer review

- Open access: articles freely available online

- High visibility within the field

- Retaining the copyright to your article

Submit your next manuscript at $\boldsymbol{\nabla}$ springeropen.com 